
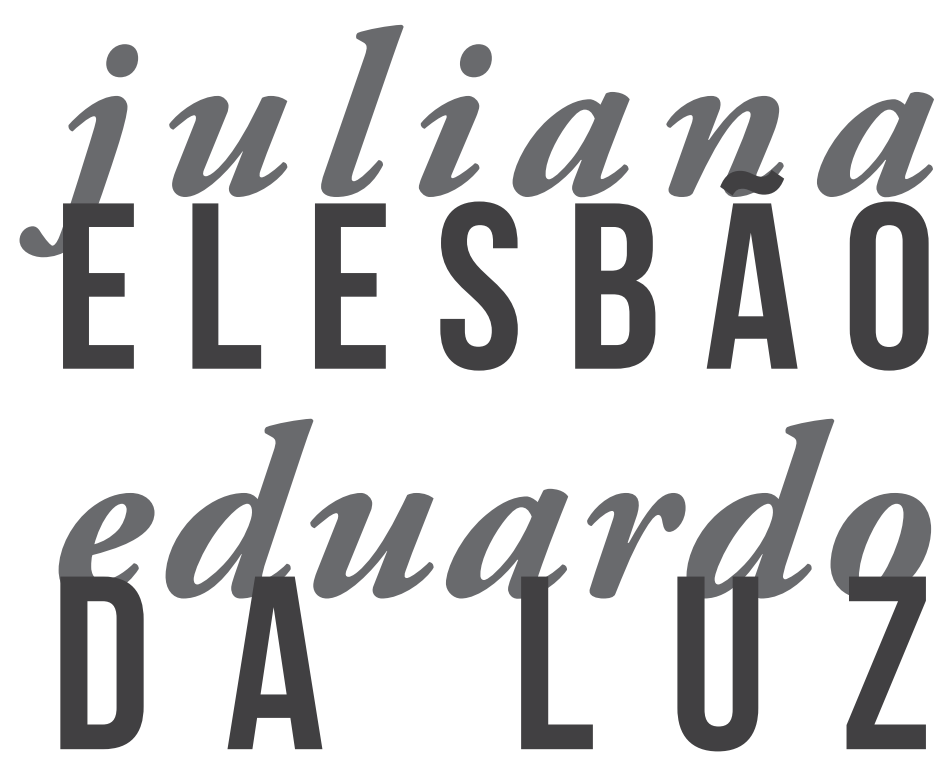

Universidade Federal do Ceará (UFC)

\title{
AS MÃOS LITERÁRIAS E A INFLUÊNCIA NO TEATRO:
}

\section{HAMLET E O MARINHEIRO}

RESUMO > Propomo-nos evidenciar como a mão literária de Fernando Pessoa, pousada sobre a máo literária de Shakespeare, seu precursor, pressionando-a, potencializa as impossibilidades de sentido da linguagem. Para tanto, tomamos como objetos desse estudo as peças teatrais O Marinheiro, de Fernando Pessoa, e Hamlet, de William Shakespeare.

PALAVRAS-CHAVE> Shakespeare; teatro; influência 


\section{AS MÃOS LITERÁRIAS \\ E A INFLUÊNCIA NO TEATRO: HAMLET E O MARINHEIRO}

\section{DA INFLUÊNCIA}

A origem de nosso trabalho toma como base, inicialmente, anotaçôes feitas por Harold Bloom e por Fernando Pessoa nas margens de livros de sua predileção: um remoto Finnegans Wake, no caso de Bloom, e um manuseado Shakespeare, de Pessoa. Nesta primeira parte, cuidaremos táo somente das anotaçôes do crítico estadunidense.

Tais comentários são-nos revelados por Harold Bloom em seu $A$ anatomia da influência, de 2011, em edição brasileira de 2013. Diz-nos amistosamente:

Um pouco mais tarde [em relação ao período de sua pós-graduação em Yale] e com menos energia, como um jovem membro do corpo docente, eu mesmo imitei [Thornton] Wilder, liderando outro seminário informal [sobre Finnegans Wake], usando então uma edição de 1958 da Viking Press, que se encontra à minha frente enquanto escrevo, cheia de anotações marginais um tanto quanto blakeanas (BLOOM, 2013, p. 145).

Já então lhe interessava o agon de James Joyce com Shakespeare. Para Bloom, o poder do escritor irlandês sobre a linguagem e a sua mitologia eram shakespearianas, e William Shakespeare já era, desde aquela época, "o Fundador": "Estaríamos aqui de qualquer modo, é claro, mas sem Shakespeare não nos teríamos enxergado como o que somos" (BLOOM, 2013, p. 22). As anotaçóes feitas por Fernando Pessoa em seu volume com as peças shakespearianas igualmente projetam um embate, este ainda mais perturbador: o agon de si
1 Mestranda do Programa de PósGraduação em Letras da UFC e Professora-tutora do ensino a distância da Universidade Aberta do Brasil/UFC Virtual.

E-mail: julianeelesbao@gmail.com

2 Professor Doutor no Departamento de Literatura, da Universidade Federal Ceará.

E-mail: eduardocrluz@gmail.com 
mesmo contra Shakespeare, instigado pelas reflexôes que naquelas páginas registrou sobre Oscar Wilde e sua "fé no estético", como Bloom viria modernamente reafirmar (BLOOM, 2013, p. 17).

Jamais saberemos as razóes que conduzem um homem da estatura intelectual de Harold Bloom, aos 80 anos de vida, a escrever um novo livro. Sendo o que ele próprio considerou seu canto do cisne, $A$ anatomia da influência, no entanto, manifesta seu desejo de esclarecer algumas formulaçôes malconcebidas por seus leitores, como, por exemplo, a ideia acima posta de que Shakespeare nos teria inventado. Essa e outras ideias haviam sido colocadas no volume $A$ angústia da influência, de 1973; nele, Bloom propôs categorias que a obra recente retoma em formulaçóes mais elaboradas: a desleitura criativa, a luta pouco gentil nos relacionamentos literários, o poetaem-um-poeta... Tania Franco Carvalhal, em texto da década de 1980, reconhece o brilho da teoria bloomiana, mas explicita supostos reducionismos:

É certo que sua proposição se autolimita ao montarse apenas com relaçáo a grandes poetas. Além disso, não examina a possibilidade de que, na construçáo do poema, coexistam influências de outra natureza que não a poética. Ocupa-se apenas com os caminhos escondidos que vão de poema a poema, analisando somente "the poet in a poet". Os aspectos formais dos poemas ficam, nessa perspectiva, relegados. Para ele, tudo se reduz a um conflito de geraçóes e a uma série de mecanismos de defesa que, acionados, regem as relaçóes intrapoéticas (CARVALHAL, 1986, p. 60).

Se, no entanto, o ainda jovem catedrático Harold Bloom trabalhava com tais instabilidades teóricas, antes disso já expunha convicçôes que carregou pela vida afora; uma delas era a de que Finnegans Wake constituía o final da busca por Shakespeare, empreendida por James Joyce. O soberano bardo de Stratford-onAvon era já o "nosso Homero", e, para Bloom, apesar de inevitável, o melhor que os dramaturgos poderiam fazer era desviar do criador de Hamlet. Fernando Pessoa, contudo, quis repensar o teatro mental 
shakespeariano, e o agon de Pessoa com Shakespeare -embora em obra menos incensada que Finnegans Wake- tem a complexidade do agon entre Joyce, seu contemporâneo, e Shakespeare.

Na peça de Pessoa, observaremos a mão literária do escritor sucessor pousada sobre a mão literária do precursor, pressionando-a, a fim de potencializar as impossibilidades de sentido pressentidas pelo rival de Shakespeare, as quais se projetam no campo do universo simbólico sustentado pela palavra. Não nos aprofundaremos na teoria poética de Harold Bloom para analisar as relaçóes estéticoliterárias entre as obras que aqui visamos a examinar, mas ela contribui, expressivamente, para a compreensão do que se pretende propor neste trabalho.

\section{A MÃO DE SHAKESPEARE E A MÃO DE PESSOA: HAMLET E}

\section{O MARINHEIRO}

Passemos, agora, às anotaçôes feitas por Fernando Pessoa. Elas se encontram nas páginas de seu exemplar da obra completa de Shakespeare. Algumas dessas anotaçóes dizem respeito ao ensaio “The Portrait of Mr. W.H.”, de Oscar Wilde. É confusa a ideia que temos de Wilde visto por Pessoa: por um lado, um falso moralista; por outro, no fragmento "O destino do gênio", é a Wilde que Pessoa nomeia. Afinal, são wildianos os esboços de certa estética apoiada no paradoxo, na dissolução do absoluto: "As únicas pessoas reais são as que nunca existiram", conhecidíssima frase de The Decay of Lying. Em Wilde, formula-se a criação de uma "personalidade literária”, maneira de representar teatralmente, em consonância com sua ideia de a vida ser ficção, e a arte, realidade. Pessoa, que sempre soube distanciar-se criticamente de seus confrades literários, levou ainda mais fundo esse processo de dramatização. Tal distanciamento crítico e tal capacidade de verticalizar experiências literárias são traços vigorosamente 
marcantes de Fernando Pessoa. A ideia de nosso trabalho nasceu daí, e é esta: apreciar esses dois traços, especificamente em relação a Shakespeare, de quem usaremos Hamlet (cujo protagonista ainda segundo nosso articulador Wilde- inventou o pessimismo de Schopenhauer). De Pessoa, usaremos $O$ marinheiro.

Parece haver dois campos de interesse para Pessoa, no que concerne ao "gentil-homem de Stratford-on-Avon": o que trata do famoso "problema shakespeariano", relativo à autoria e à identidade de William Shakespeare, e o essencialmente textual, admirado e emulado. Quanto ao primeiro, Pessoa poderia ter acolhido explicaçóes esotéricas ou motivos simplesmente secretos para o eventual disfarce do mestre inglês, mas preferiu sustentar seus argumentos sobre a natureza do gênio, segundo a qual Shakespeare seria dotado de uma "ultra-assimilação", capaz de fazê-lo apreender, intensa e profundamente, aquilo que via ou ouvia; em outras palavras, encantava-o "seu poder de observação, resumindo um todo num só aspecto de importância primacial; sua habilidade prática nascida de uma rápida compreensão das coisas...” (PESSOA, 2005, p. 311). No que respeita ao segundo campo, que se comunica naturalmente com o primeiro, mergulhemos em algumas assimilações pessoanas de Shakespeare; pensemos em desdobramentos estéticos particularizados dos dois poetas-dramaturgos, servindo-nos das relaçóes que parecem impor-se entre os dois textos.

Comecemos por Hamlet, cuja sedução e cujo brilho, em boa medida, originam-se de um jogo textual que gera um produto com a nitidez da duplicidade. As falas devem cassar o sentido das que lhes sobrevêm; os personagens dizem uma coisa que é outra: dizer é velar. Hamlet funde-se à linguagem, representa-a e, ao final, pede a Horácio que o afirme nela, ou seja, pede-lhe que compreenda ser ele uma construção dessa linguagem que o antecedeu, que o foi e que deverá sê-lo. Se estamos certos, Pessoa procederá à agudização desse processo. Em 35 Sonnets, escrito provavelmente em 1909, ele já empreendia uma análise entre o conhecimento e a linguagem. No fragmento "Os graus da poesia lírica", destacava, acerca do estilo shakespeariano, "o relevo inesperado da frase, a subtileza e a 
complexidade do dizer" (PESSOA, 1988, p. 56).

Retomando o caso de James Joyce, citado no início deste trabalho, Bloom destacava seu poder sobre a linguagem e como ultrapassava o horizonte estabelecido pela língua-linguagem enquanto instrumento de produção literária. Suas escolhas, portanto, não estavam encerradas por um conjunto opaco de significantes; pelo contrário, o escritor lança mão de sua liberdade criadora e esgota as possibilidades de significação, abolindo o caráter neutro e inerte da língua-linguagem. Joyce parecia, portanto, discordar da seguinte afirmação de Barthes, em que é perceptível a preocupação com a falta de liberdade criadora na língua-linguagem à qual estaria fadado o escritor:

[A língua] É muito menos uma provisão de materiais do que um horizonte, isto é, ao mesmo tempo um limite e uma estação. (...) $\mathrm{O}$ escritor nada retira dela, literalmente; a língua é antes para ele como uma linha cuja transgressão designará talvez uma sobrenatureza da linguagem: é a área de uma ação, a definição e a espera de um possível. (...) Ninguém pode, sem mais nem menos, inserir a sua liberdade de escritor na opacidade da língua. (...) Assim, para o escritor, a língua nada mais é do que um horizonte humano que instala ao longe certa familiaridade, toda negativa (...).

A língua está pois aquém da Literatura (BARTHES, 2004, p. 10, grifo do autor).

Pessoa, por sua vez, parece entrar em consonância com a ideia de Barthes e a extremiza; a língua-linguagem no texto dramático -pertencente, obviamente, ao conjunto semiótico literário- d'O marinheiro se restringe a ser o espaço da náo-ação, visto que tanto as personagens quanto seu estado de alma são delineados de forma exclusivamente verbal. A aparente inércia das personagens é potencializada na "teatralidade" dos signos. Na referida obra, o escritor português manifesta um discurso que ganha a configuração de um jogo exclusivo de significantes, bancado unicamente pela linguagem, sem transgredi-la. Aqui, as palavras perdem sua capacidade de criar 
e sua possibilidade de representar. Já se disse que, no drama estático pessoano, não há sequer personagens, apenas vozes. Se nossa ideia faz sentido, Pessoa aprofundou o golpe de Shakespeare, simbolizado nesta fala de Hamlet: "Realmente, tudo isto é aparência, pois são açôes que podem ser representadas pelo homem; porém, o que dentro de mim sinto, supera todas as exterioridades..." (SHAKESPEARE, 1989, p. 538).

Para Pessoa, sabemos, o que ele sentia não poderia ser transmitido. Em $O$ marinheiro, as palavras sustentam a existência apenas simbolicamente; afinal, com a pulverização de um absoluto que poderia explicá-la, nada se diz, e esse nada é o que dizem as Veladoras. Estudioso de questóes estéticas e literárias, Pessoa eleva a incomunicação de seu drama ao nível de problema da própria arte moderna, que tende a significar sua insignificação.

Relacionados a esse, há dois aspectos interligados que podem encorpar nossa proposta de que Pessoa pressionou sua mão sobre a de Shakespeare: a paralisia da ação e a estrutura do drama. Iniciemos por Hamlet. Sua imobilidade para a vingança é o centro da peça, um problema que vem atravessando os séculos: Goethe viu nela o embate entre a vontade (ligada ao querer) e a necessidade (ligada ao dever), que negará ao protagonista tanto a solução de seu conflito interior, quanto a realização de seu conflito exterior, em que o primeiro se transforma após a exigência da vingança feita pelo espírito do rei. Está em $O$ nascimento da tragédia: "O conhecimento mata a atuação, para atuar é preciso estar velado pela ilusão: tal é o ensinamento de Hamlet" (NIETZSCHE, 1993, p. 56).

A verdade é que Hamlet não se vinga nem supera a ideia de vingar-se; a furiosa atenção que o absorve e o frenético acúmulo de imagens que lhe acorrem irão levá-lo à anulação. Evidentemente, essa questáo não passou despercebida a Pessoa. Para ele, há três "espécies de atividade mental" que produzem "a falta de vontade de impulso"; e conclui, exemplificando a segunda com Hamlet: "o temperamento artístico e literário, em que a vontade é virada para dentro" (PESSOA, 2005, p. 707). Com $O$ marinheiro, Pessoa complexifica o processo 
shakespeariano, criando, já, uma peça "virada para dentro"; nela, "pode haver revelação de almas sem ação, e pode haver criação de situaçóes de inércia, momentos de alma sem janelas ou portas para a realidade" (PESSOA, 2005, p. 283).

Para o mestre português, o "grande gênio" Shakespeare interessava-se mais pela psicologia das personagens que pela estrutura das peças, ratificando o que Goethe dissera das mesmas: "elas contêm muito menos ação sensível do que palavra espiritual" (GOETHE, 2000, p. 38), ou seja, servem mais à imaginação que à visão. A "peça dentro da peça”, em Hamlet, e a história do marinheiro sonhado pela segunda Veladora, em $O$ marinheiro, são ambas estruturas em abismo, mas a metonímia de que se servem busca o inverso: na primeira, a intensificação da teatralidade; na segunda, sua anulação... É peripécia na primeira e, na segunda, o impossível clímax da arte moderna.

Os dois aspectos discutidos no parágrafo anterior ligam-nos, por via natural, à questão dos gêneros literários. Parece mesmo que Shakespeare não nos deixou textos teóricos sobre teatro, mas alguns de seus personagens o fizeram. Em Hamlet, pela voz de Polônio, o dramaturgo inglês relativiza os gêneros e suas leis de representação: "São os melhores atores do mundo, tanto para a tragédia, como para a comédia, a história, a pastoral, a pastoral-cômica, a pastoralhistórica, a histórica-trágica, a pastoral tragicômica-pastoral, cena indivisível ou poema ilimitado" (SHAKESPEARE, 1989, p. 562).

Além de relativizá-los, Shakespeare parece comprazer-se com a problematização de seus limites. A tragédia Hamlet, sob a perspectiva do pré-romantismo alemão, é um drama, tanto por privilegiar francamente a lexis (presta-se melhor à leitura), quanto pelas dificuldades ligadas à encenação (opsis), características que configuram o inverso do que, na visão goethiana, seria uma peça teatral. Se nossa linha de análise segue tendo sentido, Pessoa conduz ao extremo a complicada montagem teatral shakespeariana; com $O$ marinheiro, ele rejeitará todas as orientações do teatro representável. De seu drama estático, sem "conflito nem perfeito enredo", restará 
apenas, e emblematicamente, a literatura.

Também ao extremo será levado o humor de Hamlet, que, destaque-se, nasce da primeira fala do protagonista: "(Aside) A little more than kin, and less than kind" (1º ato, 2a cena) / "(À parte) - Um pouco mais do que parente e menos do que filho" (SHAKESPEARE, 1989, p. 538). Já está aqui o que o papel de louco lhe facultará por toda a peça: jogos de palavras e inversóes de sentido, que irão beirar o puro nonsense: kin (parente) e kind (simpático, cordial) ironizam a fala do tio, embora kind também tivesse um sentido, hoje arcaico, de "descendência”. Esse procedimento, aliás, é um dos pilares do drama; surpreso com a devolução dos presentes, Hamlet pergunta a Ofélia: "Ha, ha! are you honest?" (3o ato, 1ª cena) / "Ah, ah! És honesta?” (SHAKESPEARE, 1989, p. 568). Honest, no caso, é explorado por ambivalência: "sincera" ou, no significado arcaico, "casta" ou "virtuosa".

O dramaturgo Shakespeare sabia que o efeito sobre o espectador consistia em função decisiva no teatro, tese que afirmou na "peça dentro da peça", e o zeloso produtor Shakespeare entendia indispensável o alívio cômico, chegando a explorá-lo numa frequência e numa intensidade que punham em risco o próprio tom da peça. Como exemplo, lembremos a aparição do rei: a extrema angústia de Hamlet não o impede de dizer aos amigos "You hear this fellow in the cellarage", em que cellarage (que hoje diríamos cellar) é, rigorosamente, "porão" (!). O famoso "Hic et ubique?", que o filho dirige ao pai, não deixa de fazer ver a todos a impertinência do espírito; é como se lhe perguntasse: "Você quer que agora os homens jurem em outro lugar?”.

Schiller já fizera graves reservas a esse procedimento de Shakespeare; Goethe afirmou que a tragicidade de Romeu e Julieta chegou a pôr-se em risco pelas intervençóes cômicas de Mercúrio e da ama. Quanto a Fernando Pessoa, ele forçará a ironia shakespeariana até que ela atravesse o corpo do texto e torne-se humor radicalmente intelectual: no "falar dobrado" da ironia pessoana, as partes suplementam-se hermeticamente, e o discurso de $O$ marinheiro vai 
configurar-se como manifestação irônica da literariedade.

Em 1864, Taine observou que a história de Hamlet era o percurso de um "envenenamento moral", explicado por sua “imaginação exaltada” (TAINE, 1945, p. 282). O príncipe, na identidade demente que assume, não chega, porém, a perder-se por inteiro; apropriando-nos das palavras de Polônio, poderíamos dizer: "Embora seja pura loucura, há sensatez no que diz..." Dito de outro modo: na fala de Hamlet há um método, ainda que indecifrado, gerador de certo sentido; Polônio não o identifica porque se trata do sentido mais profundo possível: o humano. Fernando Pessoa, ao refletir sobre "a dor e o delírio do Rei Lear", que todos sentimos, diz-nos:

Porque é, então, que, sendo esse delírio tão caracterizadamente o do demente senil, o sentimos tanto nós, que não temos conhecimento desse delírio? Porque Shakespeare pôs nesse delírio só aquela parte que nele é humano, e afastou o que nele seria, ou particular do indivíduo Lear, ou especial do demente senil (PESSOA, 1988, pp. 28-29).

$O$ marinheiro, escrito numa época interessada pelo inconsciente e pelo tempo interior, fixou no leitor-espectador a impossibilidade de se encontrarem vidas coesas e a impossibilidade de um sentido único para as palavras, que, afinal, não serviam à transmissão de qualquer conteúdo.

Além desse contraponto, há ainda outro que nos parece produtivo, considerada nossa ideia motivadora: a feição místiconacionalista. Goethe, ao apontar a grandeza de Shakespeare, punha-o como um profeta, a quem nada se velava, equivalente "ao espírito do mundo". Muito já se discutiu, e ainda se discute, acerca da revelação de certos mistérios em obras shakespearianas, a qual se daria por ações muitas vezes inverossímeis, exercidas por homens ou por fenômenos. Para além disso, em Pessoa "os acontecimentos são Homens. As circunstâncias são gente" (PESSOA, 2005, p. 555). 
Não faltam ao poeta-dramaturgo português abstraçóes entificadas e personificaçóes, a ele que foi, efetivamente, um iniciado, implicado de modo visceral na aprendizagem de desaprender.

Pessoa escreveu sobre sua meta de exploração do Desconhecido, do mistério "sem nome", que "se esconde por debaixo das palavras". Especulou sobre uma Nova Era espiritual, vazada pelas lentes de um nacionalismo místico: o Quinto Império. $O$ marinheiro autoriza-nos a identificar Pátria e Poética, por via da alma lusitana de Pessoa, embora não esteja ali um Portugal empírico. De maneira análoga, em Hamlet não há uma Dinamarca empírica; Goethe já dissera que todos os personagens de Shakespeare eram “notoriamente ingleses”. Em nosso ambiente acadêmico, já são célebres estas palavras de Machado de Assis, em seu ensaio de 1873: “(...) e perguntarei mais se o Hamlet, o Otelo, o Júlio César, e Julieta e Romeu (sic) têm alguma coisa com a história inglesa nem com o território britânico, e se, entretanto, Shakespeare não é, além de um gênio universal, um poeta essencialmente inglês" (ASSIS, 1986, p. 804).

O mesmo argumento sustentou Jorge Luis Borges, no século seguinte, quando apresentou a seguinte afirmação: "Creo que Shakespeare se habría asombrado si hubieran pretendido limitarlo a temas ingleses, y si le hubiesen dicho que, como inglés, no tenía derecho a escribir Hamlet, de tema escandinavo, o Macbeth, de tema escocés" (BORGES, 1989, p. 270).

Ideias como essas de Goethe, Machado e Borges, com suas inevitáveis diferenças de tom, serão sempre convocadas para redesenhar o inesgotável tema literário do nacionalismo, místico ou não, entrevisto em $O$ marinheiro e em Hamlet.

\section{DAS CONSIDERAÇÕES FINAIS}

Este ensaio nasceu de uma imagem: palavras encostadas 
a palavras; anotaçóes de Pessoa nas páginas de Shakespeare. Tanto quanto o envolveu o "problema" da identidade de William Shakespeare, Pessoa amava Shakespeare, a ponto de saber "tão de cor aquelas falas [dos personagens shakespearianos] que ao recitálas perverte-os (escreve) sendo outros" (MOTTA, 2004, p. 77). O camaleão Shakespeare serviu de maneira para Pessoa, que viu em seu fingimento dramático um exemplo de sinceridade artística.

Além disso, observamos como a palavra imobiliza a encenação e suspende a duração temporal. Agudizando a construção de um enredo teatral sem ação, manifestado por Shakespeare, Fernando Pessoa evoca um universo simbólico que transcende o espaço da representação, impedindo uma evolução da ação dramática.

De ambos, escolhemos duas peças (poderiam ser outras) e algumas categorias (poderiam ser outras) que permitissem vislumbrar a mão de Pessoa sobre a de Shakespeare, forçando-a na direção do mistério. Words, words, words: a única verdade é que Shakespeare continuará minando ideias, e Pessoa seguirá verticalizando-as. Porque a literatura é isto: mais que uma questão de vida e de morte. Quanto a nós, leitores de ambos, continuaremos nos sonhando, absolutamente personagens.

\section{REFERÊNCIAS BIBLIOGRÁFICAS}

ASSIS, Machado de. Obra completa. Rio de Janeiro, Nova Aguilar, 1986. Vol. 3.

BARTHES, Roland. Que é a escrita?. In: O grau zero da escrita: seguido de novos ensaios críticos. Tradução de Mario Laranjeira. 2a ed. São Paulo, Martins Fontes, 2004.

BLOOM, Harold. A anatomia da influência: literatura como modo 
de vida. Tradução de Ivo Korytowski e Renata Telles. Rio de Janeiro, Objetiva, 2013.

A angústia da influência: uma teoria da poesia.

Tradução de Arthur Nestrovski. Rio de Janeiro, Imago, 1991.

BORGES, Jorge Luis. Obras completas. Buenos Aires, Emecé, 1989. Vol. 1.

CARVALHAL, Tania Franco. Literatura comparada. São Paulo, Ática, 1986.

GOETHE, Wolfgang. Escritos sobre literatura. Rio de Janeiro, 7Letras, 2000.

MOTTA, Marcus Alexandre. Desempenho da leitura: sete ensaios de literatura portuguesa. Rio de Janeiro, 7Letras, 2004.

NIETZSCHE, Friedrich. O nascimento da tragédia. Rio de Janeiro, Companhia das Letras, 1993.

PESSOA, Fernando. Antologia de estética, teoria e crítica literária. Rio de Janeiro, Tecnoprint, 1988.

Obra em prosa. Rio de Janeiro, Nova Aguilar,

2005.

Obra poética. Rio de Janeiro, José Aguilar,

1969.

SHAKESPEARE, William. Hamlet. London, Penguin Books, 2001. Obra completa. Rio de Janeiro, Nova

Aguilar, 1989. Vol. 1.

TAINE, Hipolito. Historia de la literatura inglesa. Buenos Aires, Editorial Americalee, 1945. 


\section{ABSTRACT}

We intend to demonstrated how Fernando Pessoa's literary hand, laid on Shakespeare's literary hand and pressing it, potentiates the impossibilities of meaning of the language. In order to do this, we have taken as objects of that study the plays $O$ Marinheiro by Fernando Pessoa and Hamlet by Shakespeare.

\section{KEYWORDS}

Shakespeare; theater; influence 